\title{
Correction to: Risk premia in the term structure of crude oil futures: long-run and short-run volatility components
}

\author{
Naomi Boyd ${ }^{1} \cdot$ Bingxin $\mathrm{Li}^{2} \cdot \mathrm{Rui} \mathrm{Liu}^{3}$ (D) \\ ๑) Springer Science+Business Media, LLC, part of Springer Nature 2022

\section{Correction to: Review of Quantitative Finance and Accounting https://doi.org/10.1007/s11156-021-01032-w}

The original version of the article has contained a mistake in Table 2 and it has been corrected in this erratum.

The original article has been updated.

The corrected Table 2 is given below

The original article can be found online at https://doi.org/10.1007/s11156-021-01032-w.

Rui Liu

liur2@duq.edu

Naomi Boyd

naomi.boyd@mail.wvu.edu

Bingxin Li

bingxin.li@mail.wvu.edu

1 John Chambers College of Business and Economics, West Virginia University, 256 Business and Economics Building, Morgantown, USA

2 John Chambers College of Business and Economics, Center for Innovation in Gas Research and Utilization, West Virginia University, 224 Business and Economics Building, Morgantown, USA

3 Palumbo Donahue School of Business, Duquesne University, 811 Rockwell Hall, Pittsburgh, USA 
Table 2 Parameter estimates

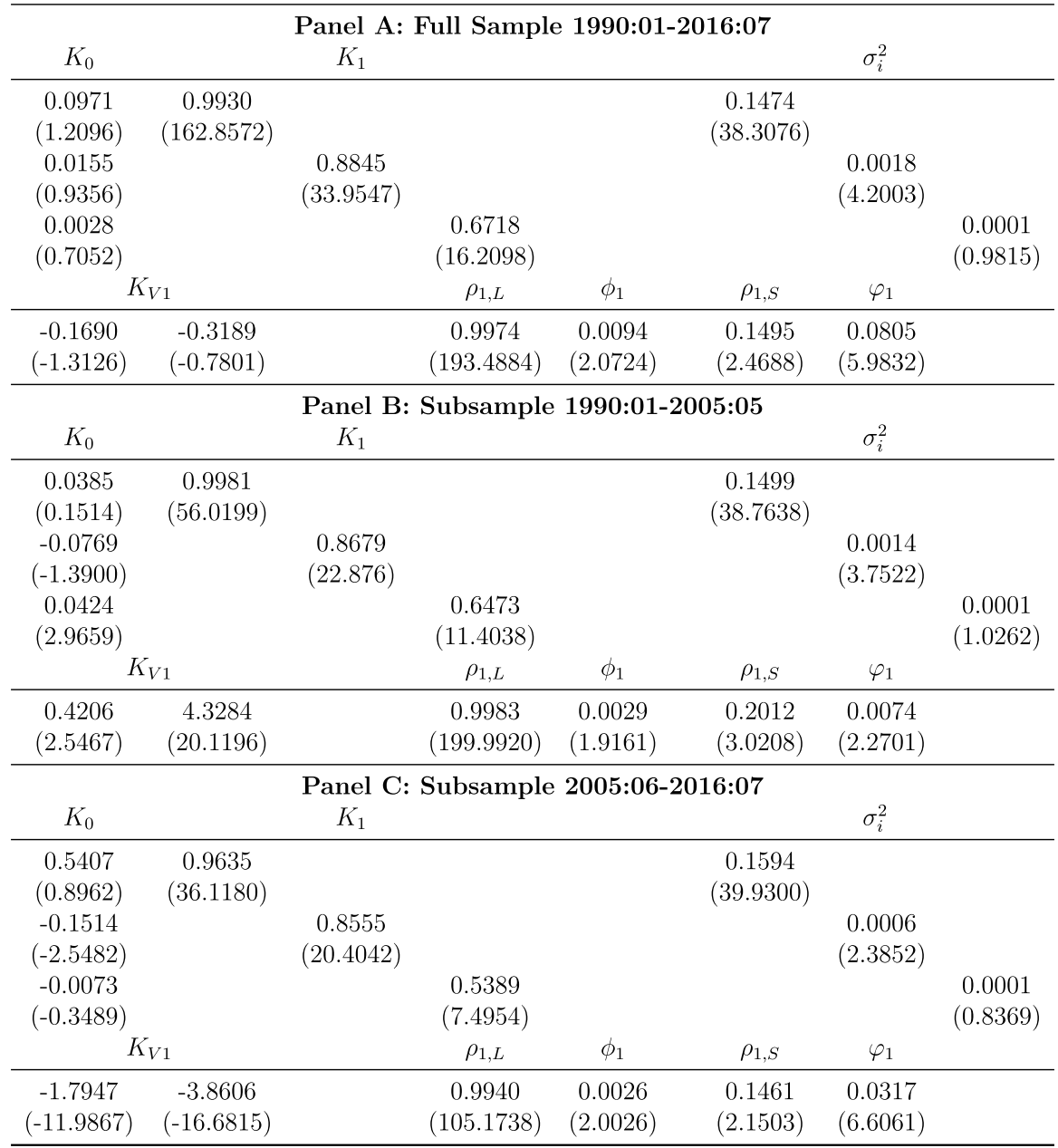

This table presents the estimated parameters ( $\mathrm{t}$-statistics are in parentheses) for the term structure model with long-run and short-run volatility components using the full sample and two subsamples. We use the Chicago Mercantile Exchange (CME) WTI crude oil futures settlement price on the last business day of each month for maturities of one to twelve months in the estimation. The full sample period is from 1990:01 to 2016:07. The first subsample is from 1990:01 to 2005:05. The second subsample is from 2005:06 to $2016: 07$

Publisher's Note Springer Nature remains neutral with regard to jurisdictional claims in published maps and institutional affiliations. 